\title{
COURSE ASSESSMENT PRACTICES AND STUDENT LEARNING STRATEGIES IN ONLINE COURSES
}

\author{
Bridget D. Arend, Ph.D. \\ University of Denver
}

\begin{abstract}
Perhaps the most promising and understudied aspect of online education is course assessment. Course assessment is important because it has a strong impact on learning and is an indicator of the quality of learning occurring in a class. In the online environment, methods of assessment can be very different. However, the online education literature is currently lacking empirical data about the general status of assessment practices or how those practices relate to student learning. This article lays the groundwork for future studies by providing a description of formative and summative assessment and learning strategies in 60 online courses and suggesting some ways that assessment practices lead to different types of learning. In this study, instructors appear to follow effective practice by using multiple and alternative assessment methods, dispersing grades over time, and providing timely and frequent feedback to students. Students report focusing on relatively more complex learning strategies, such as elaboration and critical thinking over rehearsal. However, online instructors need to ensure that assessments are used strategically and that feedback is productive and able to be acted upon by students.
\end{abstract}

\section{KEYWORDS}

Course Assessment, Summative Assessment, Formative Assessment, Learning Strategies, Critical Thinking

\section{INTRODUCTION}

In the online environment, the lack of physical space and face-to-face contact between instructors and students leads to different ways of assessing learning in a class. Online, the instructor cannot tell whether the student is in attendance unless he or she is actively contributing something to the virtual class. As a result, online instructors grade for participation, typically assigning between 10 and $25 \%$ of the course grade for discussions participation [1]. To prevent dishonesty as well as to create a learner-centered environment, students are typically awarded grades based on a variety of assignments, quizzes, papers, tests, group projects, and discussion contributions [2]. Grading also occurs throughout a class, rather than at one or two points in a term. This increased emphasis on continual and alternative assessment methods has great potential to increase the transparency of the learning process and improve learning.

Classroom assessment is important because it has a strong impact on learning. The way an instructor approaches assessment influences the way students perceive the class, the material for study, and their own work [3]. Most importantly, assessment practices influence students by directing their attention to particular aspects of course content and by specifying ways of processing information [4]. Students concentrate their efforts towards whatever content or cognitive skills they believe will be tested [5, 6]. So not only does assessment influence what content students spend time learning, but also the type of learning occurring. Different forms of assessment encourage different types of learning [7, 8, 9]. Even the 
form of an exam or essay question can affect how students study [10]. In the online environment specifically, it has already been shown that the nature of online discussion questions [11], or the emphasis on grading criteria [12], can influence the type and quality of online discussion responses.

One way of exploring the type and quality of student learning is through the cognitive processes students use to study, called learning strategies. Learning strategies are the specific cognitive activities and thought processes that students undertake when studying for a class, such as underlining text, making an outline, or applying knowledge to a new situation. They have been defined broadly as cognitive processes that are intentional and under control of the learner [13]. They have also been referred to as surface or deep approaches to learning $[14,15,16]$.

Numerous studies have explored and supported the link between the assessment practices in a course and the learning strategies students use in a course [17, 18, 19, 20]. Studies have illustrated not only how different assessment methods encourage different learning strategies, but how different learning strategies result in qualitatively different learning outcomes. For example, students who read text at a deep level are better able to answer questions about the meaning and conclusions of the text, while surface strategies result in mainly descriptive answers [14]. Simple methods used to study for objective tests are not as effective for long-term retention as more complex methods used to study for essay tests [9]. And surface approaches are found to be effective for recalling detail whereas deep approaches are effective for the development of more complex and meaningful knowledge structures $[8,16]$. In general, when students focus on more complex cognitive and metacognitive processes over routine rehearsal processes, they are more academically successful [21, 22]. The learning strategies students use in a course ultimately influence their overall learning outcomes.

Thus, a framework emerges whereby assessment practices are very important in determining the type of learning taking place in a course. The type of learning is an indicator of the quality of learning, and online learning environments by their very nature lend themselves to new and different assessment practices. Clearly there is a need to explore assessment practices and learning in the online environment. However, little literature exists about online assessment practices [6, 23, 24, 25]. It has been noted that most of the literature about online assessment is in the form of guidelines and case studies or explores a specific assessment practice within one or a small number of classes [26]. Only a few studies have taken a broad look across disciplines at the typical assessment practices that are occurring in online courses in higher education, but most have not explored how these new assessment practices influence the learning strategies of students [27, 28]. To respond to increased calls for accountability and to support emerging exploration in this area, more empirical data is needed about the status of online assessment. This study was designed to fill this gap in the literature and contribute to an understanding of what assessment looks like online and how assessment influences learning.

The purpose of this study was to describe how course assessment practices relate to learning strategies for students taking an online course at the community college level. This involved describing the status of assessment practices in terms of summative and formative assessment, describing the use of student learning strategies, and exploring which course assessment practices are related to which learning strategies. The summative and formative assessment and learning strategy variables used in this study, as well as their origins, will be described next.

\section{A. Summative and Formative Assessment}

Just as learning is a complex process with many variables involved, course assessment is complex and involves many aspects and dimensions. Course assessment is typically theorized in terms of summative 
and formative assessment. The theoretical difference between the two is a matter of purpose whereby summative assessment is designed to make evaluative judgments of student learning and formative assessment focuses on using feedback and information to improve learning [29]. Assessment scholars agree that most of the literature about summative assessment in higher education focuses on issues of broader accountability rather than the learning that occurs within the classroom [30,31]. Perhaps the best source of identifying effective summative practice grounded in literature comes from the former American Association for Higher Education (AAHE). In 1992, AAHE pulled its best minds together to create nine well-supported Principles of Good Practice for Assessing Student Learning. Although the AAHE principles also focus on the program and institutional level, they are useful for understanding assessment within the classroom. The principle that is most encompassing and most useful for classroom learning is AAHE principle \#2: "Assessment is most effective when it reflects an understanding of learning as multidimensional, integrated, and revealed in performance over time” [32]. Angelo [33] describes this principle in more depth by dividing it into four complementary components: use multiple methods; use multiple assessors; assess over time; and assess multiple dimensions of learning. Each of these four components has its own basis in assessment literature. It is these four aspects of effective practice in summative assessment that form the variables used in this study to describe summative assessment.

In contrast to the evaluative objectives of summative assessment, formative assessment is used for purposes other than making evaluations and recording course grades. Even though formative assessment is discussed and studied more than summative assessment, it is also a concept without a widely accepted meaning or overarching formal theory [34]. It has been broadly defined as including all feedback and information used to modify teaching and learning activities [35]. Most of the categorizations of formative assessment focus on the procedural aspect of feedback occurring between instructors and students. The process of effective feedback is often described as a loop whereby feedback is given and acted upon by both instructors and students [34]. Four general dimensions of effective feedback that emerge from the literature include: instructors providing frequent feedback, instructors providing precise feedback, instructors changing course content or teaching methods based on student feedback, and students actually acting on instructor feedback [5, 34, 36, 37]. These four dimensions provide a description of effective practice and were used as the formative assessment variables in this study.

\section{B. Learning Strategies}

The learning strategy taxonomy used in this study was developed by the National Center for Research in Postsecondary Teaching and Learning (NCRIPTAL) at the University of Michigan [9]. The taxonomy includes five cognitive and metacognitive learning strategies: rehearsal, elaboration, organizational, critical thinking, and metacognitive self-regulation. Each strategy is represented by various study activities or cognitive processes. For example, rehearsal strategies assist the attention and encoding process and include such tasks as memorizing, reciting items from a list, copying material, or underlining passages. In the past, rehearsal strategies were found to be those most frequently used by college students [21]. Although this taxonomy is not based on a continuum, in this study rehearsal strategies are considered the most basic type of learning strategy, representing the surface approaches to learning. The other learning strategies are considered generally more complex learning strategies. Elaboration strategies help students store information into long-term memory by building internal connections and include using imagery, identifying key words, paraphrasing, and creating analogies. Organizational strategies help the learner select appropriate information and construct connections within the information to be learned. Examples are clustering, creating mnemonics, and selecting main ideas such as outlining or diagramming. Critical thinking strategies help students develop new ways of thinking about course content such as applying prior knowledge to new situations, transferring knowledge, reaching decisions, and making evaluations. Finally, metacognitive self-regulation strategies identify how students control and modify 
their cognitive processes. These planning, regulating, and monitoring strategies include such tasks as setting goals, self-testing, regulating the speed of reading, and using test-taking strategies. These five learning strategies are used in this study to describe the type of learning occurring online and to determine any relationships that exist between assessment practices and learning.

\section{METHODOLOGY}

\section{A. Participants}

The site for this study was the Colorado Community Colleges Online (CCCOnline), an online entity comprised of thirteen member colleges in the Colorado Community College system, Dawson Community College of Montana, Northwest Missouri State University, and Pickens Tech of Denver. This institution offers over 300 educational and occupational online courses to nearly 5000 students each semester [38]. Like other online institutions, CCCOnline enrollments have grown tremendously since its inception in 1999. This institution was chosen as the sampling frame of this study because of its large enrollment, variety of disciplines represented, experience in offering online courses, and diverse representation of instructors and students across Colorado. It was felt that this institution represents a fairly typical online experience for community college students, useful for the descriptive purposes of this study.

Sixty courses were randomly selected from the Spring 2005 semester, stratified by academic program. The academic programs included Accounting, Arts and Humanities, Business and Economics, Computer Information Systems, Criminal Justice, Early Childhood Education, Languages and Literatures, Math, Physical and Environmental Sciences, and Social and Behavioral Sciences. Average course enrollment was 20 students and most of the courses were 100-level (60\%) and offered for 3 credit hours (67\%). The researcher collected data about assessment practices from each course. Fifty-one instructors completed an instructor survey. These instructors had been teaching college-level courses an average of 13 years and have been teaching online an average of five years. Courses with instructors who were teaching online for the first or second time were excluded from the sample to eliminate any differences due to instructor inexperience. In addition, 411 students completed a student survey. Student participants were mostly female (75\%), White non-Hispanic (81\%), and U.S. citizens (96\%). However, student ages ranged from 18 to 69 and over $80 \%$ were employed either part-time or full-time. Almost half had some form of degree or certificate. Most of the students were not only working adults but were comfortable with online technology and were taking classes as part of a degree.

The student response rate was low at $37 \%$. However, comparisons of demographic variables between the study sample and the population of CCCOnline students during the same semester showed that the students responding to the survey were representative of the student population with the one exception that the sample may contain more students with certificates or degrees. In addition, one-way analysis of variance was used to test for response bias among three waves of student respondents. Four of the five learning strategy subscale means on the student survey showed no significant difference between the three student response groups. Only the organization subscale showed potential response bias between the first wave of student respondents and the next two waves, and therefore any results emerging from the organization subscale must be accepted with caution.

\section{B. Instrumentation and Data Collection}

Three surveys were pilot tested during the Fall 2004 semester and used in the Spring of 2005 to collect data on formative assessment, summative assessment, and student learning strategies. The researcher was given access to the sampled courses and completed an observational survey to collect information about types of assignments, formative and summative assessment practices, and grading policies. An instructor 
survey collected self-reported data about formative assessment feedback practices and dimensions of learning assessed within a course. Both of these surveys were created by the researcher after an extensive literature review to include the salient components of effective practice in summative and formative assessment.

Students were given a survey with 31 items from the Motivated Strategies for Learning Questionnaire (MSLQ) [39]. The MSLQ is widely used to compare student learning strategies to different educational variables. It was designed with subscales that can be used modularly at the course level. The questionnaire asked students to self-report on a scale of 1-7 their frequency of use of rehearsal, elaboration, organization, critical thinking, and metacognitive self-regulation learning strategies. For example, a rehearsal strategy question was, "I make lists of important terms for this course and memorize the lists." The elaboration strategy included such questions as, "I try to apply ideas from course readings in other class activities such as discussions." And a question for the critical thinking strategy subscale was "Whenever I read an assertion or conclusion in this class, I think about possible alternatives." Certain items on the MSLQ were modified to update the wording for the online medium and to measure the frequency with which students report using learning strategies. Reliability coefficients for the revised questionnaire were deemed appropriate. Cronbach's alphas for each subscale were: rehearsal, .745; elaboration, .783; organization, .751; critical thinking, .787; and metacognitive self-regulation, .788. This study also included a follow-up qualitative phase designed to explain and add detail to the quantitative findings, but results are not detailed in this article.

\section{RESULTS}

\section{A. Summative Assessment}

The first goal of this study was to provide a description of the summative and formative assessment practices in the online courses in this sample. Summative assessment was described by detailing four effective practices: using multiple methods, using multiple assessors, assessing over time, and assessing multiple dimensions of learning. $\mathrm{n}$ terms of methods, these courses used an average of five different assignment methods. Table 1 lists the methods used and percentage of course grade assigned. The methods used are typical for a college course but also include experiential and alternative methods. Group projects and collaborative activities, methods highly touted in the online assessment literature, were not used at all in this sample. Discussion was the most common method; however exams received the highest percentage of course grades.

Table 1. Assessment Methods Used and Percentage of Course Grade

\begin{tabular}{lcc}
\hline \multicolumn{1}{c}{ Method } & $\begin{array}{c}\text { Courses using } \\
\text { this method }\end{array}$ & $\begin{array}{c}\text { Average \% of } \\
\text { course grade }\end{array}$ \\
\hline Discussion & 59 & 17.1 \\
Exam & 50 & 44.7 \\
Written assignment & 38 & 23.5 \\
Final/Midterm & 23 & 19.2 \\
Experiential Assignment & 20 & 18.1 \\
Problem Assignment & 19 & 22.0 \\
Quiz & 13 & 3.5 \\
Paper & 13 & 23.2 \\
Journal & 10 & 15.1
\end{tabular}




\begin{tabular}{lcc} 
Presentation & 6 & 12.5 \\
Pretest & 6 & 1.0 \\
Project & 4 & 12.8 \\
Peer Review & 3 & $4.6^{\mathrm{a}}$ \\
Form & 1 & 1.0 \\
Group Project & 0 & -- \\
\hline Note. N = 60. & \\
a'Peer review grades were part of discussion grade and are estimated based \\
on proportion of discussions.
\end{tabular}

With regard to the use of multiple assessors, instructors themselves primarily assessed learning. However, self grading was a strong component in these courses. All courses used instructor grading, $65 \%$ used a form of self-grading, and only 5\% used peer grading. In terms of assessing over time, student learning was assessed throughout a course. Assignments were due an average of 10 out of 15 weeks. However, discussions were usually graded for ongoing participation over all 15 weeks, so students typically needed to actively participate in discussions during each week of the course. The final aspect of summative assessment, assess multiple dimensions of learning, will be discussed below along with student learning strategies.

\section{B. Formative Assessment}

The distinction between formative and summative assessment practices, although detailed in theory, becomes blurred in online courses. Because there is no face-to-face class time online, it is difficult to expect students to do assignments unless they are part of the course grade, limiting the use of purely formative assignments. In this study, some formative assessment occurred in the form of non-graded quizzes and exercises. Many of these were supplemental content materials developed by textbook publishers and courses linked to these assignments as a means of giving students extra practice or review. There was an average of seven non-graded assignments in each course, although $30 \%$ of the courses did not use them at all.

Formative assessment was primarily described in this study by analyzing student and instructor feedback throughout the course. Feedback was determined from the instructor's perspective using four aspects of effective practice taken from the literature: frequency of feedback, precision of feedback, changes in course or teaching, and student use of feedback. In terms of frequency of feedback, instructors reported interacting and providing feedback to students often and quickly. The vast majority of instructors, $94 \%$, said they had more than 10 individual interactions with each student during the course, $22 \%$ claiming more than 40 interactions. Ninety-six percent of instructors also said they responded to students in less than 48 hours, $60 \%$ saying their responses came within 24 hours. Instructors also claimed to provide constructive feedback to students regularly. The majority, $86 \%$, claimed to usually or always use student feedback to identify misunderstandings and to give students advice to improve their work. Similarly, regarding precision of feedback, instructors felt strongly that they provide precise feedback to students. Ninety-six percent say they usually or always give students feedback based on a good understanding of their knowledge of the course material, while $91 \%$ do so based on a good understanding of their writing and thinking skills.

Instructors reported much lower uses of using feedback from students to change course content or teaching methods. Only 54\% said they usually or always modify teaching methods or techniques while 
only $40 \%$ report regularly modifying or adding course materials. Twenty-three percent usually or always used student feedback to add or change course assignments, and only a few more, $42 \%$, said the same for adding or changing discussion questions. Finally, instructors were asked how often they felt their students actually use the feedback given to them and were somewhat pessimistic about this use of feedback. Only slightly more than half felt that students usually or always used instructor feedback to make any real changes, such as: making revisions to assignments, 55\%; seeking meaning from instructor comments, 59\%; gaining a better understanding of the course material, 63\%; adjusting their learning strategies, 55\%; or achieving more advanced thinking and learning processes, 55\%.

\section{Student Learning Strategies}

To provide a description of student learning, students were asked to self-report how often they used different learning activities or cognitive processes that fall under five different learning strategies on a scale of 1 to 7 where $1=$ never and $7=$ always. Elaboration was the most used learning strategy with a mean score of 4.88, meaning students spent more time elaborating on course material than on other strategies. Metacognitive self-regulation strategies had the next highest use, followed by critical thinking. Students reported using rehearsal and organization strategies the least, averaging just slightly less than half the time (See Table 2).

Table 2. Means and Standard Deviations for Students' Reported Learning Strategy Use and Instructor Goals for Learning Strategy Use

\begin{tabular}{lcccc}
\hline & \multicolumn{2}{c}{ Student use } & \multicolumn{2}{c}{ Instructor goal } \\
\cline { 2 - 5 } Learning strategy & Mean & SD & Mean & $S D$ \\
\hline Rehearsal & 3.79 & 1.33 & 4.90 & 1.70 \\
Elaboration & 4.88 & 1.10 & 6.08 & 1.15 \\
Organization & 3.86 & 1.36 & 4.96 & 1.44 \\
Critical thinking & 4.29 & 1.21 & 5.84 & 1.34 \\
Metacognitive self-regulation & 4.72 & 0.86 & 5.63 & 1.52 \\
\hline
\end{tabular}

Note. $\mathrm{N}=411$ for student sample. $\mathrm{N}=51$ for instructor sample.

As a means of determining if these courses assessed multiple dimensions of learning, an aspect of effective practice in summative assessment, instructors were also asked how often their students should be using the five learning strategies in their course using the same language and scale as the student survey. The desired learning goals of these instructors showed similar emphasis to students' reported use. Elaboration was the most desired learning strategy with a mean score of 6.08, meaning instructors wanted students to elaborate on course material nearly always. Critical thinking and metacognitive self-regulation were also relatively strong goals. Rehearsal and organization strategies both appeared to be lesser goals of these instructors. The emphases for both instructors and students were the same, although instructors' desired goals were generally higher than students' reported use for each strategy.

\section{Relationship between Assessment Practices and Learning Strategies}

This study also sought to explore how summative and formative assessment practices relate to the use of student learning strategies. Most formative assessment variables and general summative assessment variables did not show significant relationships to learning strategy use. Instead, it was the use of individual assessment methods such as discussions or papers that were significantly related to learning strategies. All significant relationships found are displayed in Table 3. No significant findings were found for the rehearsal strategy. Only a few significant findings emerged for the organization and metacognitive 
self-regulation strategies and were not deemed notable. A number of variables were found to be significant with the elaboration strategy, indicating that the use of discussions and journals are related to more elaboration strategy use, and the use of pretests, finals/midterms, and non-graded assignments are related to less elaboration strategy use.

Most notably, a comprehensible theme emerged regarding the critical thinking strategy. Discussions, written assignments, and papers were all positively related to the use of critical thinking. Finals/midterms were negatively related to critical thinking use. In addition, non-graded assignments were negatively related to critical thinking as shown in the number of assessors in a course, the number of non-graded assignments, and the number of non-graded methods. There is a pattern that emerges with the critical thinking strategy, although the sizes of the correlations are small. Thus while there are many factors that influence learning strategy use, it appears that the more a course used discussions, written assignments and papers, the more students used critical thinking strategies. Conversely, the more a course used finals/midterms and non-graded assignments, the less students reported spending time thinking critically.

Table 3. Significant Relationships between Course Assessment Variables and Student Learning Strategy Variables

\begin{tabular}{|c|c|c|}
\hline Learning strategy & Positive relationship & Negative relationship \\
\hline Rehearsal & -- & -- \\
\hline Elaboration & $\begin{array}{l}\text { Number of assessments } \\
r(408)=.101^{*}, p=.041 \\
\text { Number of discussions } \\
r(408)=.181^{* *}, p=.000 \\
\text { Number of journals } \\
r(408)=.102^{*}, p=.040\end{array}$ & $\begin{array}{l}\text { Number of pretests } \\
r(408)=-.131^{* *}, p=.008 \\
\text { Number of finals/midterms } \\
r(408)=-.142^{* *}, p=.004 \\
\text { Number of non-graded methods } \\
r(408)=-.147^{* *}, p=.003\end{array}$ \\
\hline Organization & $\begin{array}{l}\begin{array}{l}\text { Use student feedback to } \\
\text { correct } \\
\text { misunderstandings } \\
r(342)=.124^{*}, p=.022\end{array}\end{array}$ & -- \\
\hline \multirow[t]{2}{*}{ Critical thinking } & $\begin{array}{l}\text { Number of discussions } \\
r(410)=.151^{* *}, p=.002\end{array}$ & $\begin{array}{l}\text { Number of final/midterms } \\
r(410)=-.098^{*}, p=.047\end{array}$ \\
\hline & $\begin{array}{l}\text { Number of written } \\
\text { assignments } \\
r(410)=.102^{*}, p=.039 \\
\text { Number of papers } \\
r(410)=.115^{*}, p=.020\end{array}$ & $\begin{array}{l}\text { Number of non-graded } \\
\text { assignments } \\
r(410)=-.167^{* *}, p=.001 \\
\text { Number of non-graded methods } \\
r(410)=-.179^{* *}, p=.000 \\
\text { Number of assessors } \\
r(410)=-.118^{*}, p=.017\end{array}$ \\
\hline $\begin{array}{l}\text { Metacognitive } \\
\text { self-regulation }\end{array}$ & -- & $\begin{array}{l}\text { Number of pretests } \\
r(409)=-.124^{*}, p=.012\end{array}$ \\
\hline
\end{tabular}




\section{E. Motivation}

Motivation has been shown to be linked to performance along with learning strategies [22]. Although motivation was not a central part of this study, it was taken into account as a possible contributing factor. The initial value placed on the subject or course by a student, often called entering course value, has been shown to be the strongest predictor of cognitive and metacognitive learning strategy use [40]. Accordingly, students were asked their main reason for taking their online course. The majority of these students, 70\%, said they took this class because it was required. Others reported taking the class because they want or need to learn the material, $16 \%$; or because the course seemed interesting, $11 \%$; or because they thought it would be easier online, $2 \%$. Analysis of variance showed the mean differences between groups representing why a student took the course were statistically significant at $p<.01$ for three of the learning strategy subscales: rehearsal, $F(3,405,408)=3.96, p=.008$; elaboration, $F(3,405,408)=4.45$, $p=.004$; and critical thinking $F(3,407,410)=5.44, p=.001$. Post hoc tests for all three subscales showed motivation did play a role for these learning strategies in that students who thought online courses would be easier showed lower reported use of these strategies. However, these results should not influence overall study results as only $2 \%, 10$ of 411 , students took the course for this reason.

\section{F. Limitations}

As with any research study, there are certain limitations that should be noted. This study attempts to create a picture of typical assessment practice within online courses. However, it only represents the practices of one institution at the community college level. Although the online environment is unique in that an entire course and all its interactions can be observed by an outside researcher, certain aspects of the study such as the use of formative assessment practices and student learning strategies were collected from self-reported measures. As already mentioned, the response rate for the student survey was representative of the population, but was low, and the role of student motivation was not directly explored. In addition, the instrument used to determine learning strategies was originally designed for the face-to-face classroom environment. Although the constructs of learning remain the same, it is possible that there are different emphases or even additional learning strategies that exist within the online environment, such as collaboration and discussion strategies, that are not included in this taxonomy. There is likely more to be learned about online learning strategies than may be shown through the use of this instrument.

\section{SUMMARY/CONCLUSIONS}

Course assessment is important in determining the type and quality of learning occurring in a class. Because assessment is different online, and little literature exists about online assessment practices, this study helps lay a foundation for future studies by providing a description of online assessment and learning and suggesting ways that the two are related. To begin with, the results of this study allow a picture to be drawn of typical assessment practices in online courses at Colorado community colleges. In brief, a typical course would consist of 29 assignments and use five different assessment methods. Assignments would be due in at least 10 of the 15 weeks. The course would likely use seven non-graded assignments but there would be no group activities beyond discussions. The instructor would say the goals of the course require the use of all the learning strategies explored in this study and students would report to use all those strategies with similar emphasis. The instructor would interact with each individual student well over 10 times during the course, responding to comments and questions within 24 to 48 hours. And although the instructor would claim to frequently provide specific and precise feedback to students, he or she would feel that students are using that feedback only about half the time. The instructor would also not be making many changes to the course during the semester. 


\section{A. Summative Assessment}

The status of summative assessment in these online classes appears for the most part to be in line with the four areas of effective practice explored in this study. These courses use a variety of assignments and methods. Online methods of exams, discussions, written assignments, problem assignments, experiential activities, and others tap different cognitive processes. Many larger assignments are even broken down into smaller pieces focusing on different aspects and graded over time. These classes appear to tap multiple dimensions of learning because students claim to use a variety of learning strategies. Multiple assessment methods that assess multiple dimensions of learning allow students to both challenge their weaknesses and draw on their strengths. Also, these classes assessed learning over 15 weeks. Such continuous assessment allows instructors to provide relevant feedback and gives students the opportunity to learn from their mistakes [41, 42]. In essence, a course where student work is graded though a midterm and final exam would be considered less beneficial to student learning than one where student work is graded in many ways throughout the semester [32]. This latter example is what seems to be the norm in these online classes.

One area of possible concern with summative assessment is the number of assignments used in a course. Although multiple, smaller assignments are deemed better than just a few high-stakes assignments, there is indication that the number of assignments in some of these classes could be too high. Some courses used 50, 60, and even 90 assignments in a 15-week period. In a course with too many short assignments, students are at risk of focusing their attention on the accumulation of a quantity of assignments rather than more complex and complete understandings of course material [43]. An instructor grading this many assignments for 20 students would likely be inclined to grade for quantity over quality. This aspect of assessment was not explored in depth, but it appears that although more assignments may be better than too few, online instructors need to be cautious of using an excess of assignments.

Another area for potential improvement in summative assessment is the use of multiple assessors. Only two of the 60 courses in this study used any form of peer review and none used peer grading techniques or collaborative projects. This finding was surprising in light of the numerous benefits attributed to peer review [44] and collaborative activities in online education [45, 46, 47]. Also, although over half of these online classes used self-assessed activities in the form of non-graded assignments, most of these assignments appeared to be added with little support from instructors regarding their use. In self grading, even adult learners need guidance and direction to become self-directed learners and to learn to use resources effectively [48]. Textbook publishers are making their content more marketable by creating numerous non-graded supplemental activities. However, adding these assignments without guidance simply because they are available may not always be the best course of action for student learning.

\section{B. Formative Assessment}

The status of formative assessment in terms of effective practice in student-instructor feedback was also fairly encouraging in these courses. The online instructors in this study reported to provide timely, frequent, and precise feedback to students. Because instructors are spending their time responding to students rather than in class conducting lectures and teaching activities, the individualized nature of their feedback is likely the case. Online instructors in general report that they know their students better than they would in a larger on-campus class [49]. This more relevant, reflective, and specific feedback is seen as much more beneficial for student learning [50,51]. While this study does not speak directly to the quality of the feedback given, the presence of regular feedback appears to be the norm online.

However, the actual use of this frequent feedback was not as strong. Instructors did not appear to make many changes to their courses. Online instructors are known to continually revise their courses [1]. Yet 
less than half of the instructors in this study reported to frequently make changes to the course including adjusting assignments or discussion questions. This could be due to the nature of the courses and adjunct faculty in this sample. Courses predesigned by a team of developers and taught by adjuncts keep a large number of courses more manageable, but can reduce the ability of instructors to adjust the course to meet the needs of current students. Adjusting assignments and teaching techniques based on an emerging understanding of students is an essential part of formative assessment [43].

Similarly, instructors in this study felt that students only utilized instructor feedback about half the time. Students must seek meaning and act on feedback if it is to ultimately be effective [5]. This means students should have not only the desire but the opportunity to learn from instructor comments and suggestions. Although instructors cannot control student desires, they can ensure students have regular opportunities to act on feedback and learn from their mistakes. As with the other feedback variables, this was not explored from the students' perspective. However, there appears to be some disparity between the amount of specific feedback provided by instructors and the use of this feedback by students.

\section{Learning Strategies}

There are many ways to explore learning. Students' use of different learning strategies provides insight into the type and quality of learning occurring in a course. In this study, students claimed to be using a variety of the five learning strategies explored. Rehearsal and organization strategies were used the least across courses. Similarly, instructors said they wanted students to be doing these strategies less than the other strategies. To some extent, this could be due to the absence of a means to test for memorization online. In many online courses, exams are considered open book and questions test for skills other than knowledge retention. Also, because there is no lecture time, many courses have lecture notes, instructor comments, or orienting diagrams that highlight key points. These aids may replace the need for students to use organization strategies. Two of the highest reported uses of learning strategies and goals of instructors were the elaboration and critical thinking strategies. The use of these strategies involves obtaining some initial knowledge of course content and taking it to the next step of applying that information or developing a new way of thinking about it. From this study, online courses appear to focus assessments on a student's ability to access and utilize information and resources, rather than to organize knowledge or retain it for an exam. In today's ever-changing global economy, higher education is being asked to produce knowledge workers who can use resources to continually adapt and improve their knowledge and skills rather than memorize [52]. When the MSLQ was created in the 1980s, surface rehearsal strategies were the most commonly used strategy by college students [21]. However these online courses show a focus on more complex learning strategies.

Metacognitive self-regulation strategies were also a strong goal of instructors and had high student use. Because online courses have no weekly class time and require self-reliance, it is no surprise that selfregulation skills would be a big component. However, it should be noted that self-regulation strategies take time to develop and need support to do so [53]. While online students are expected to use selfregulation strategies, they still likely need assistance transitioning the responsibility of learning to themselves. In addition, there may likely be some additional collaborative learning strategies occurring regularly in online classes that did not appear within the confines of this study.

\section{Course Assessment Practices and Learning Strategies}

This study also sought to explore how assessment practices relate to student learning strategies. Although many of the learning strategies showed significant relationships with a few assessment variables, the most relevant and interesting relationships were found with the critical thinking strategy. Small correlation 
sizes indicate that influencing student learning is a complex undertaking with many variables involved. However, if critical thinking is an important goal of an online course, there are some methods that appear likely to lead to more critical thinking strategy use among students. These relationships were also supported and explored in more depth by a qualitative phase of this study that is not presented here. In essence, written assignments, longer papers, and discussions have the explicit purpose of making students spend time formulating their own ideas about course concepts. Making these assignments a high percentage of the course grade and using a number of them should be linked to higher uses of critical thinking. On the other hand, using more non-graded assignments seems to encourage strategies other than critical thinking. In this study, these types of assignments tend to focus on retention, knowledge, or procedural skills. Such skills may be the focus of some classes, but most of the courses in this study had at least some critical thinking objectives for students. To put it plainly, if instructors want students to spend time thinking critically, they should use assignments that explicitly ask students to focus their study efforts on critical thinking tasks.

Assessment is important in determining the type and quality of learning occurring in a course. Because assessment can be so different online, there is a clear need for more empirical study in this area. There are many ways to conceptualize and study assessment. This article lays the groundwork for future studies by providing a description of various dimensions of summative and formative assessment in online courses and identifying some potential aspects for optimism and for improvement. The courses in this study use multiple and alternative methods, disperse grades over time, and instructors provide timely and frequent feedback. These assessment practices ask students to focus on, and students report to focus on, relatively more complex learning strategies such as elaboration and critical thinking over rehearsal. However, online instructors need to continually ensure that assignments are used only if they actively contribute to the kind of learning desired and that the tremendous amount of feedback given is productive, beneficial for learning, and able to be acted upon by students. In the end, instructors should be strategically using course assessment to concentrate student efforts on activities that explicitly bring out the learning strategies desired.

\section{REFERENCES}

1. Anderson, T. and F. Elloumi. Theory and Practice of Online Learning. Athabasca, Canada: Athabasca University, 2004.

2. Jarmon, C. Testing and assessment at a distance. In M. Boaz, B. Elliot, D. Forshee, D. Hardy, C. Jarmon and D. Olcott (Eds.), Teaching at a Distance: A Handbook for Instructors, 55-63. League for Innovation in the Community College and Archipelago Productions, 1999.

3. Brookhart, S. M. The Relationship of Classroom Assessment to Student Effort and Achievement in the College Classroom: Pilot Study Technical Report. American Educational Research Association Conference Proceedings, Chicago, IL, 1997.

4. Doyle, W. Academic Work. Review of Educational Research 53(2): 159-199, 1983.

5. Black, P. and D. Wiliam. Assessment and classroom learning. Assessment in Education 5(1): 7-74, 1998.

6. Bull, J. and C. McKenna. Blueprint for Computer-Assisted Assessment, London: RoutledgeFlamer, 2004.

7. Gipps, C. V. Beyond Testing: Towards a Theory of Educational Assessment. London: Falmer Press, 1994.

8. Hynd, C., J. Holschuh and H. Nist. Learning complex scientific information: Motivation theory and its relation to student perceptions. Reading and Writing Quarterly 16: 23-57, 2000.

9. McKeachie, W. J., P. R. Pintrich, Y. G. Lin and D. A. F. Smith. Teaching and Learning in the College Classroom: A Review of the Research Literature. Ann Arbor, MI: University of Michigan, 1986. 
10. Entwistle, N. Recent research on student learning. In J. Tait and P. Knight (Eds.), The Management of Independent Learning, 97-112. London: Kogan Page, 1996.

11. Meyer, K. A. Evaluating online discussions: Four different frames of analysis. Journal of Asynchronous Learning Networks, 8(2): 101-114, 2004.

12. Swan, K., J. Schenker, S. Arnold and C. Kuo. Shaping Online Discussion: Assessment Matters. The $12^{\text {th }}$ Sloan-C International Conference on Online Learning, Orlando, FL, 2006.

13. Pintrich, P. R. A Process-oriented view of student motivation and cognition. In J. S. Stark and L. A. Mets (Eds.), Improving Teaching and Learning Through Research, 65-79. Jossey-Bass, 1988.

14. Marton, F. and R. Saljo. On qualitative differences in learning: Outcome and process. British Journal of Educational Psychology 46: 4-11, 1976.

15. Entwistle, N. and P. Ramsden. Understanding Student Learning. London: Croom Helm, 1983.

16. Biggs, J. B. Approaches to the enhancement of tertiary teaching. Higher Education Research and Development 8(1): 7-25, 1989.

17. Eley, M. G. Differential Adoption of Study Approaches within Individual Students. Higher Education 23: 231-254, 1992.

18. Gibbs, G. The CNAA improving student learning project. Research and Development in Higher Education 14: 8-19, 1993.

19. Ramsden, P. Learning to Teach in Higher Education. London: Routledge, 1992.

20. Prosser, M. and K. Trigwell. Understanding Learning and Teaching: The Experience in Higher Education. Buckingham: The Society for Research into Higher Education and Open University Press, 1999.

21. Pintrich, P. R. The dynamic interplay of student motivation and cognition in the college classroom. Advances in Motivation and Achievement: Motivation Enhancing Environments 6: 117-160, 1989.

22. Pintrich, P. R. and E. V. deGroot. Motivational and self-regulated learning components of classroom academic performance. Journal of Educational Psychology 82(1): 33-40, 1990.

23. Liang, $\mathbf{X}$. and $\mathbf{K}$. Creasy. Classroom assessment in web-based instructional environments: Instructors' experience. Practical Assessment, Research \& Evaluation 9(7): 2004. http://pareonline.net/getvn.asp?v=9\&n=7.

24. Robles, M. and S. Braathen. Online assessment techniques. Delta Pi Epsilon 44(1): 39-49, 2002.

25. Comeaux, P. Assessing Online Learning. Boston, MA: Anker, 2005.

26. Meyer, K. A. Quality in distance Education: Focus on on-line learning. ASHE-ERIC Higher Education Report 29(4). Hoboken, NJ: Wiley Periodicals, 2002.

27. Dirks, M. How is assessment being done in distance education? NAU/web.98 Conference, Flagstaff, AZ, 1998.

28. Galante, D. Web-based mathematics: An examination of assessment strategies implemented in the online mathematics classroom. Dissertation Abstracts International 64(04): 1202A. (UMI No. 3088022), 2002.

29. Knight, P. T. Summative assessment in higher education: Practices in disarray. Studies in Higher Education 27(3): 275-286. 2002.

30. Banta, T. W., and Associates. Building a Scholarship of Assessment. San Francisco: Jossey-Bass, 2002.

31. Ewell, P. T. An emerging scholarship: A brief history of assessment. In T. W. Banta and Associates (Eds.), Building a Scholarship of Assessment, 3-25. Jossey-Bass, San Francisco, 2002.

32. Astin, A. W., T. W. Banta, K. P. Cross, E. El-Khawas, P. T. Ewell, P. Hutchings, et al. Nine Principles of Good Practice for Assessing Student Learning. American Association for Higher Education, http://www.aahe.org/assessment/principl.htm. (Also available http://www.cord.edu/dept /assessment/nineprin.pdf.)

33. Angelo, T. A. Relating exemplary teaching to student learning. New Directions for Teaching and Learning 65: 57-64, 1996.

34. Yorke, M. Formative assessment in higher education: Moves toward theory and the enhancement of pedagogic practice. Higher Education 45: 477-501, 2003. 
35. Black, P. and D. Wiliam. Inside the black box: Raising standards through classroom assessment. Phi Delta Kappan 80(2): 139-144, 1998.

36. Charman, D. Issues and impacts of using computer-based assessments (CBAS) for formative assessment. In S. Brown, J. Bull and P. Race (Eds.), Computer-Assisted Assessment in Higher Education, 85-94. London: Kogan Page, 1999.

37. Elwood, J. and V. Klenowski. Creating communities of shared practice: The challenges of assessment use in learning and teaching. Assessment and Evaluation in Higher Education 27(3): 243256, 2002.

38. Welschmeyer, D., J. Patrick and L. Cheney-Steen. Assuring Quality in Online Courses. Teaching with Technology (TWT) Conference, Denver, CO, 2004.

39. Pintrich, P. R., D. A. F. Smith, T. Garcia and W. J. McKeachie. A Manual for the Use of the Motivated Strategies for Learning Questionnaire (MSLQ). Ann Arbor, MI: Regents of the University of Michigan, 1991.

40. Pokay, P. and P. C. Blumenfeld. Predicting achievement early and late in the semester: The role of motivation and the use of learning dtrategies. Journal of Educational Psychology 82(1): 41-50, 1990.

41. Kerka, S. and M. E. Wonacott. Assessing Learners Online: Practitioner File. Washington, D.C.: Office of Educational Research and Improvement, 2000.

42. Morgan, C. and M. O'Reilly. Assessing Open and Distance Learners. London: Kogan Page, 1999.

43. Torrance, H. and J. Pryor. Investigating Formative Assessment: Teaching, Learning and Assessment in the Classroom. Buckingham: Open University Press, 1998.

44. Wolfe, W. J. Online Student Peer Reviews. Association for Computing Machinery's SIGITE '04, Salt Lake City, UT, 2004.

45. Palloff, R. M. and K. Pratt. Building Learning Communities in Cyberspace. San Francisco: JosseyBass, 1999.

46. Garrison, D. R. and T. Anderson. E-Learning in the $21^{\text {st }}$ Century: A Framework for Research and Practice. London: RoutledgeFalmer, 2003.

47. Swan, K., J. Shen and R. Hiltz. Assessment and collaboration in online learning. Journal of Asynchronous Learning Networks 10(1): 45-62, 2006.

48. Weinstein, C. E. and R. E. Mayer. The teaching of learning dtrategies. In M. Wittrock (Ed), Handbook of Research on Teaching, 315-327. New York: Macmillian, 1986.

49. Boaz, M., B. Elliott, D. Foshee, D. Hardy, C. Jarmon and D. Olcott. Teaching at a Distance: A Handbook for Instructors. Mission Viejo, CA: League for Innovation in the Community College and Archipelago Productions, 1999.

50. Bloom, B. S., J. T. Hastings, and G. F. Madaus., Handbook on Formative and Summative Evaluation of Student Learning. New York: McGraw Hill, 1971

51. Brown S. and P. Knight. Assessing Learners in Higher Education. London: Kogan Page, 1994.

52. Albright, P. If we don't build it, who will come? Higher education, state workforce, and economic development. Western Policy Exchanges: 1-6, 2005.

53. National Research Council. Knowing What Students Know: The Science and Design of Educational Assessment. Washington D.C.: National Academy Press, 2001.

\section{ACKNOWLEDGEMENTS}

The information in this paper is adapted from a dissertation study completed by Bridget Arend (2006). Previous versions of this paper were presented at the 2006 Sloan-C International Conference on Asynchronous Learning Networks and the 2006 Professional and Organizational Development Network in Higher Education Conference. 


\section{ABOUT THE AUTHOR}

Bridget Arend is Research and Assessment Analyst for the Center for Teaching and Learning and Adjunct Faculty at the University of Denver. She received her PhD in Higher Education and Adult Studies from the University of Denver in 2006. She also teaches and consults in the areas of assessment, learning, and online education. She has 15 years experience in instructional design, research and evaluation, and faculty development in K-12, higher education, and corporate environments and has published and presented about various topics associated with online education.

\section{APPENDIX I}

Variables Collected Through Researcher Course Observations

\section{Variables}

\begin{tabular}{cl}
\hline 1 & Course ID \\
2 & Credit hours \\
3 & Number of students (from enrollment statistics) \\
4 & Academic program \\
6 & Course level \\
a & For each assignment within the course: \\
b & $\quad$ Method, in instructor's words \\
c & $\quad$ Assessor (instructor, self, peer, other) \\
d & $\quad$ Number of (for that assignment) \\
e & $\quad$ Placement (week(s) assessed within course) \\
f & $\quad$ Points towards final grade \\
g & $\quad$ Percentage of final grade \\
7 & Total number of summative assignments \\
8 & Total number of summative methods used \\
9 & Number of assessors used \\
10 & Number of weeks assessed \\
11 & Number of weeks assessed, including ongoing discussions \\
12 & Total number of non-graded assignments \\
13 & Total number of non-graded methods used \\
14 & Percentage of grade for each assignment method \\
15 & Detail of assignment instructions (high, moderate, low) \\
16 & Detail of discussion instructions (very detailed, general guidelines, basic instructions) \\
17 & Researcher comments/observations about the course \\
\hline
\end{tabular}

